Pediatr. Res. 17: 183-187 (1983)

\title{
Chemotaxis in Childhood
}

\author{
OLCAY YEGIN ${ }^{(35)}$ \\ Immunology Laboratory, Hacettepe Children's Hospital, Institute of Child Health, Hacettepe University, \\ Ankara, Turkey
}

\begin{abstract}
Summary
Developmental aspects of monocyte and neutrophil chemotaxis were evaluated by the agarose and the Boyden chamber methods. Simultaneous measurements of both the distances and the cell counts were carried out by the agarose method.

Before 6 years of age monocyte chemotaxis values, determined by the Boyden chamber method, were significantly lower than those of adults. The difference between adults and children were more marked before the age of 1 year $(56 \pm 14 \mu \mathrm{m} N=48$ in 0 -1 year, $85 \pm 17 \mu \mathrm{m} N=25$ in adults $P<0.0001$ ).

Neutrophil chemotaxis, determined by the agarose method, was significantly lower than adults in newborns. Values increased gradually thereafter and reached to adult levels after the age period of 2-5 years. Before 6 years of age chemotactic indices (chemotaxis/random migration) for both cell count and distance were also significantly lower than adults.
\end{abstract}

In 20 individuals, neutrophil chemotaxis was assessed simultaneously by both the agarose and the Boyden chamber methods and showed good correlation in reference to distance measurements $(P<0.01)$. Cell count and distance measurements, by the agarose method, were also well correlated $(P<0.01)$ but agarose method and cell count determination seemed to be most sensitive. Distance/cell count ratio was found to be significantly higher in newborns $(1.61 \pm 0.45)$ when compared with adults $(1.13 \pm 0.16)$ $(P<0.001)$.

Use of age-matched controls in the evaluation of chemotaxis in children, particularly under 5 years of age, is imperative.

\section{Abbreviations}

MN, monocyte

PMN, polymorphonucleocytes

ZAS, zymosan activated serum

Prompt directed migration of neutrophils and monocytes to the site of microbial invasion plays an important role in the prevention and control of infection. Availability of new in vitro methods permitted rapid, easy, and reproducible assessment of chemotaxis. Consequently, there has been a remarkable proliferation of reports on the clinical cases of chemotactic defects. Inasmuch as chemotactic defects can occur as a result of humoral inhibitors (25) or defective generation of chemotactic factors $(13,21)$, they are usually the result of intrinsic cellular abnormalities that can be either congenital or acquired. Most of the reported chemotactic deficiency diseases are encountered in the childhood period ( 7 , 22). Recent studies have clearly shown that developmental alterations occur in neutrophil and monocyte chemotaxis during the neonatal period $(12,15,17,19,20,24,26)$ but studies on the developmental aspects of chemotaxis after the neonatal period are rare $(1,11,14)$.

This study was undertaken to explore the development of neutrophil and monocyte chemotaxis during childhood.

\section{MATERIALS AND METHODS}

Monocyte chemotaxis was determined in nine separate cord blood samples, 103 normal infants and children ( $0-17$ years), and
25 healthy adults (18-36 years) by the Boyden chamber method. Neutrophil chemotaxis was evaluated in nine separate cord blood samples, 119 normal infants and children (0-17 years), and 46 healthy adults (18-36 years) by the agarose method. None of the children or adults were given any drugs or vitamins at least 3 days before the test. Individuals with malnutrition or with signs of infection were not included. After the approval of Human Experimentation Committee of Hacettepe University, informed consent was obtained from the families and children.

Heparinized (20 units $/ \mathrm{ml}$ ) peripheral blood samples were obtained from a peripheral vein. Mononuclear and polymorphonuclear rich cells were obtained by the two-step technique described by Boyum (5). After washing three times in medium 199 (28), PMNs were suspended in the same medium at a final concentration of $3 \times 10^{7} / \mathrm{ml}$ for the agarose and $5 \times 10^{6} / \mathrm{ml}$ for the Boyden chamber methods. Mononuclear cells contained approximately 75\% lymphocytes, $25 \%$ monocytes (MN) and less than 3\% PMNs. $\mathrm{MNs}$ were further estimated by peroxidase staining (9) and MN counts were adjusted to $3 \times 10^{6} / \mathrm{ml}$ in med 199 .

Chemotactic factor. Pooled $\mathrm{AB}$ serum was activated with $\mathrm{Zy}$ mosan-A (29) at the concentration of $5 \mathrm{mg} / \mathrm{ml}$ at $37^{\circ} \mathrm{C}$ for $45 \mathrm{~min}$ and this zymosan activated serum (ZAS) was divided into small aliquots $(0.2 \mathrm{ml})$ and stored at $-20^{\circ} \mathrm{C}$ until use. The same ZAS sample was used during the entire study period.

\section{CHEMOTAXIS ASSAYS}

Boyden chamber method. Monocyte chemotaxis was assessed by the Boyden chamber technique (4) using Skyes Moore chambers (30). Briefly, $0.5 \mathrm{ml} \mathrm{MN}$ cell suspension $\left(1.5 \times 10^{6}\right)$ was added to the upper chamber separated from the chemotactic factor $(0.5 \mathrm{ml}$ of $10 \%$ ZAS in med 199) by a millipore filter of $5 \mu \mathrm{m}$ pore size (31). After incubation for $90 \mathrm{~min}$ at $37^{\circ} \mathrm{C}$ in a $5 \% \mathrm{CO}_{2}$ atmosphere, chemotaxis was evaluated by the leading front method described by Zigmond and Hirsch (27). The distance between the upper surface of the filter and the three most advanced cells in five different fields of each filter were measured and the mean of the values were given in microns.

PMN chemotaxis was determined simultaneously by the Boyden chamber and the agarose method in nine separate cord blood samples, 4 newborns, 12 infants, and 15 adults. Briefly, $0.5 \mathrm{ml}$ PMN cell suspension $\left(2.5 \times 10^{6}\right)$ was added to the upper chamber. The lower compartment was filled with $0.5 \mathrm{ml}$ of $10 \%$ ZAS. Threemicron pore size millipore filters ( 31 ) were used and the incubation time was $1 \mathrm{~h}$. The results were evaluated by the method described above.

Agarose method. Neutrophil chemotaxis was assessed by the agarose method described by Nelson et al. (18) with some modifications. Five $\mathrm{ml}$ of $1 \%$ agarose (32) in med 199 supplemented with $0.2 \%$ bovine serum albumin and $750 \mu \mathrm{g} / \mathrm{ml} \mathrm{NaHCO}_{3}$ is plated in a disposable plastic petri dish (33) $50 \mathrm{~mm}$ in diameter. Six series of three wells, $3 \mathrm{~mm}$ in diameter and $3 \mathrm{~mm}$ apart, were made. Ten microliters of ZAS was added to the outer wells $1 \mathrm{~h}$ before the cell suspension in order to establish a chemotactic gradient. Ten microliters of cell suspensions $\left(2.5 \times 10^{5}\right)$ were added to the central wells and $10 \mu \mathrm{l}$ of med 199 to all the inner wells. Med 199 was added to both the inner and outer wells in order to evaluate the random migration. The agarose plates were 
incubated for $3 \mathrm{~h}$ at $37^{\circ} \mathrm{C}$ in a $5 \% \mathrm{CO}_{2}$ atmosphere. Chemotaxis was evaluated with the aid of an ocular grid of $(50 \times 10) \times(50$ $\times 10) \mu$ m diameters. The grid was centered on the apex of the cell well and both the distance of the three most advanced cells, in one horizontal plane, measured from the edge of the central well, and cell counts in the vertical ocular grid area were determined by moving the ocular grid towards the outer well. Previous experiments showed good correlation between total cell counts and cell counts in the ocular grid area (correlation coefficient $r=0.934$, data not shown here). Replicate determinations differed less than 10\%. All assays were made in duplicates. In the statistical comparisons the $P$ values $<0.05$ were considered to be significant and statistical significance was determined by both the student $t$ test and Wilcoxon rank sum test (8)

\section{RESULTS}

Results of monocyte chemotaxis studies in different age periods are shown in Figure 1. Monocyte chemotaxis increased gradually during early childhood and reached to adult levels after a $2-5$ year period.

PMN chemotaxis was significantly lower than adults in cord blood and newborns (Fig. 2). PMN chemotaxis increased gradually after this period and distance measurements reached adult values in a 2-5 year period, whereas cell counts were still signifi- cantly lower than adults. Differences between adults and children were more striking in reference to cell count determinations than distance measurements (Fig. 2). Both cell count and distance parameters reached to adult values in a 6-10 year period.

PMN chemotaxis, when tested by the Boyden chamber method, was also significantly lower in 14 newborns $(54 \pm 12 \mu \mathrm{m})$ when compared with 15 adults $(75 \pm 11 \mu \mathrm{m})(P<0.001)$.

The Boyden chamber and the agarose methods correlated well ( $r=0.713, P<0.01)$ as pertaining to distance measurements. Cell counts and distance measurements in the agarose method also showed good correlation $(r=0.846 P<0.001)$ both in the newborn and adult groups, but the distance/cell count ratio was significantly higher $(1.61 \pm 0.45)$ in newborns than in adults: $(1.13$ $\pm 0.16)(P<0.001)$

Chemotactic indices (chemotaxis/random migration) in children for both cell count and distance were found to be significantly lower than adults until 6 years of age (Fig. 3 ).

Neutrophil random migration showed conflicting results with the two methods and three evaluation types. There was no difference in distance measurements between adults and newborns in the Boyden chamber $(21 \pm 3.4 \mu \mathrm{m}$ in 13 newborns, $20 \pm 3.6 \mu \mathrm{m}$ in 15 adults, $P>0.05)$ and agarose methods $(340 \pm 72 \mu \mathrm{m}$ in 21 newborns, $400 \pm 122 \mu \mathrm{m}$ in 46 adults $P>0.05$ ). But before 6 months of age, agarose method and cell counts $(181 \pm 41$ in 21 newborns and $181 \pm 57$ in eight $2-5$-month-old infants, $264 \pm 122$

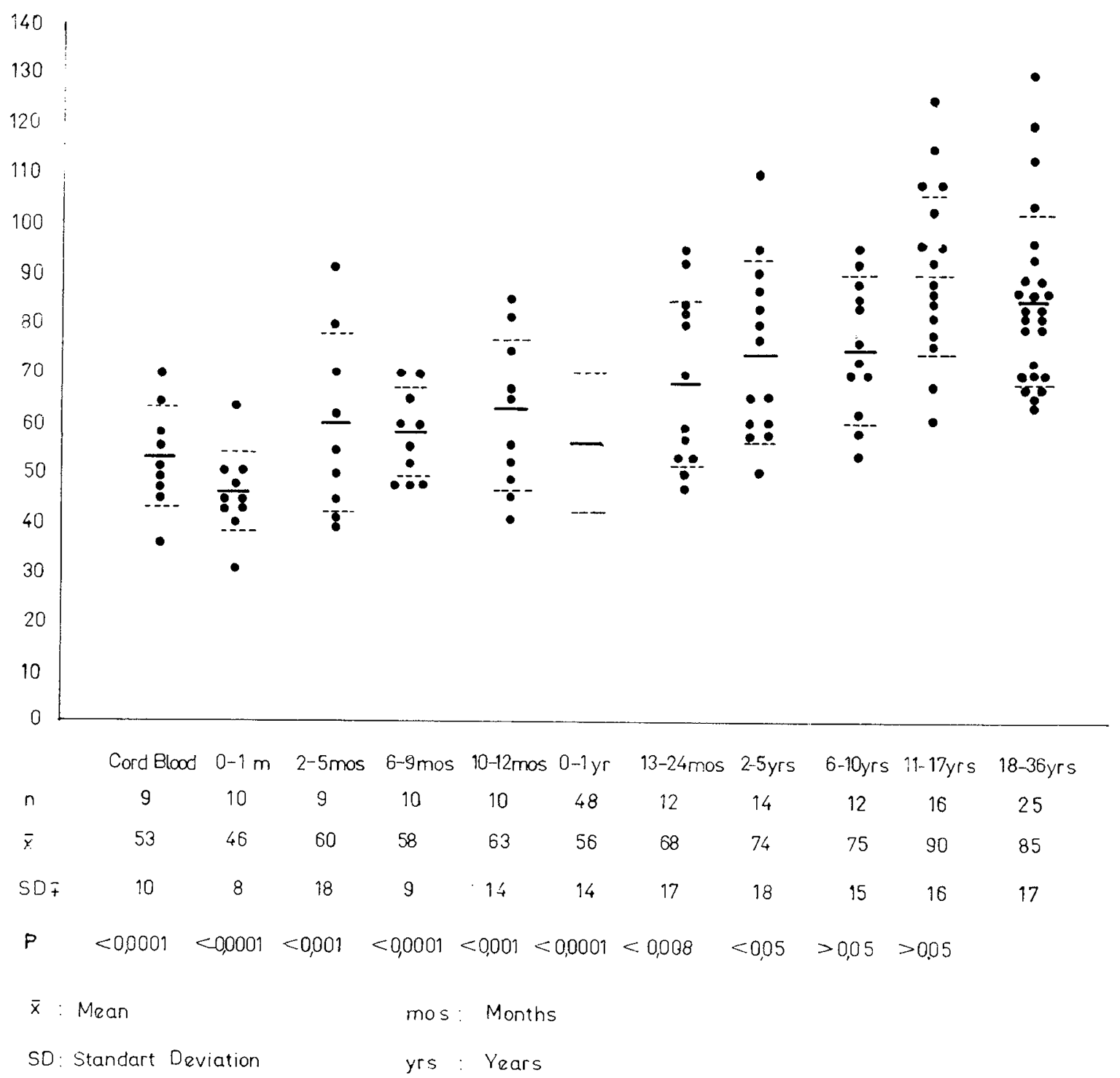

Fig. 1. Monocyte chemotactic activity at different ages (Boyden chamber method). 


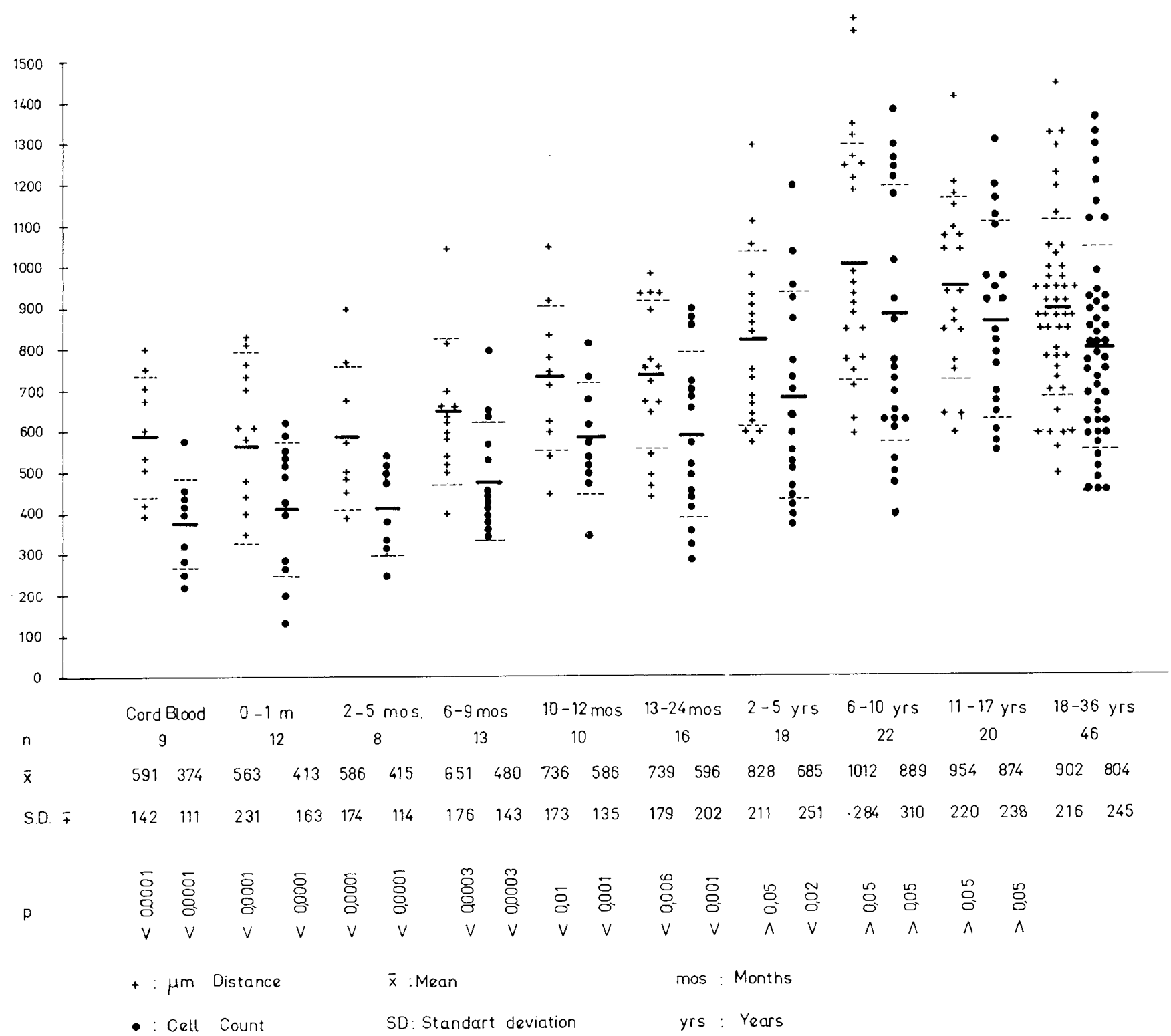

Fig. 2. Neutrophil chemotactic activity at different ages (Agarose method).

in 46 adults $P<0.03$ ) were found to be significantly lower than adults. In all parameters of neutrophil random migration, no difference was found between adults and children after 5 months of age.

\section{DISCUSSION}

This study confirms and extends previous studies that demonstrate developmental defects in monocyte and neutrophil chemotaxis of the human newborn.

There are scantly and contradictory studies available with regard to the chemotactic mobility of monocytes in healthy newborns and children $(11,12,14,19,26)$. The depressed chemotactic activity of monocytes during the early childhood period described in this study is in agreement with the report of Klein et al. (11) and Weston et al. (26). In the study of Klein et al. (11) monocyte chemotaxis reached adult values after 11 years of age, whereas in this study monocyte chemotaxis reached adult values after 6 years. This variation can be explained by differences of the methods applied, genetic, and socioeconomic differences between the two populations studied. Data reported by Marodi et al. (14) are somewhat difficult to interpret. They found decreased monocyte chemotaxis in newborns when the lower surface evaluation method was used. This difference disappeared in the 3-5-year age group. When leading front evaluation was used, no difference was found between all age groups tested.

The results of this study are parallel to previous data reported from many laboratories, which demonstrated relative deficiency of neutrophil chemotaxis in newborns studied by different chemotaxis methods $(1,11,17,19,20,24)$. With the exception of the newborn period, studies on neutrophil chemotaxis during early childhood are rare $(1,11)$.

Klein et al. (11) reported that neutrophil chemotaxis values during the entire childhood period are significantly lower than those of adults. Our results obtained in neonatal period agree with this report but neutrophil chemotaxis reached to adult values after a 2-5-year period in our study. Differences in methodology and reasons explained above in monocyte chemotaxis could be responsible for the differences between these two studies. It is of interest that Al-Nakeeb et al. (1) using a different method for measuring chemotaxis noted a similar age dependency.

Chemotactic indices (chemotaxis/random migration) for both distance and cell count were also found to be significantly lower than adults before the 6-10-year age group. This finding leads to the suggestion that neutrophil orientation to chemotactic gradient might be defective during this period as suggested by Miller and Cheung (17).

The Boyden chamber and the agarose methods showed good 


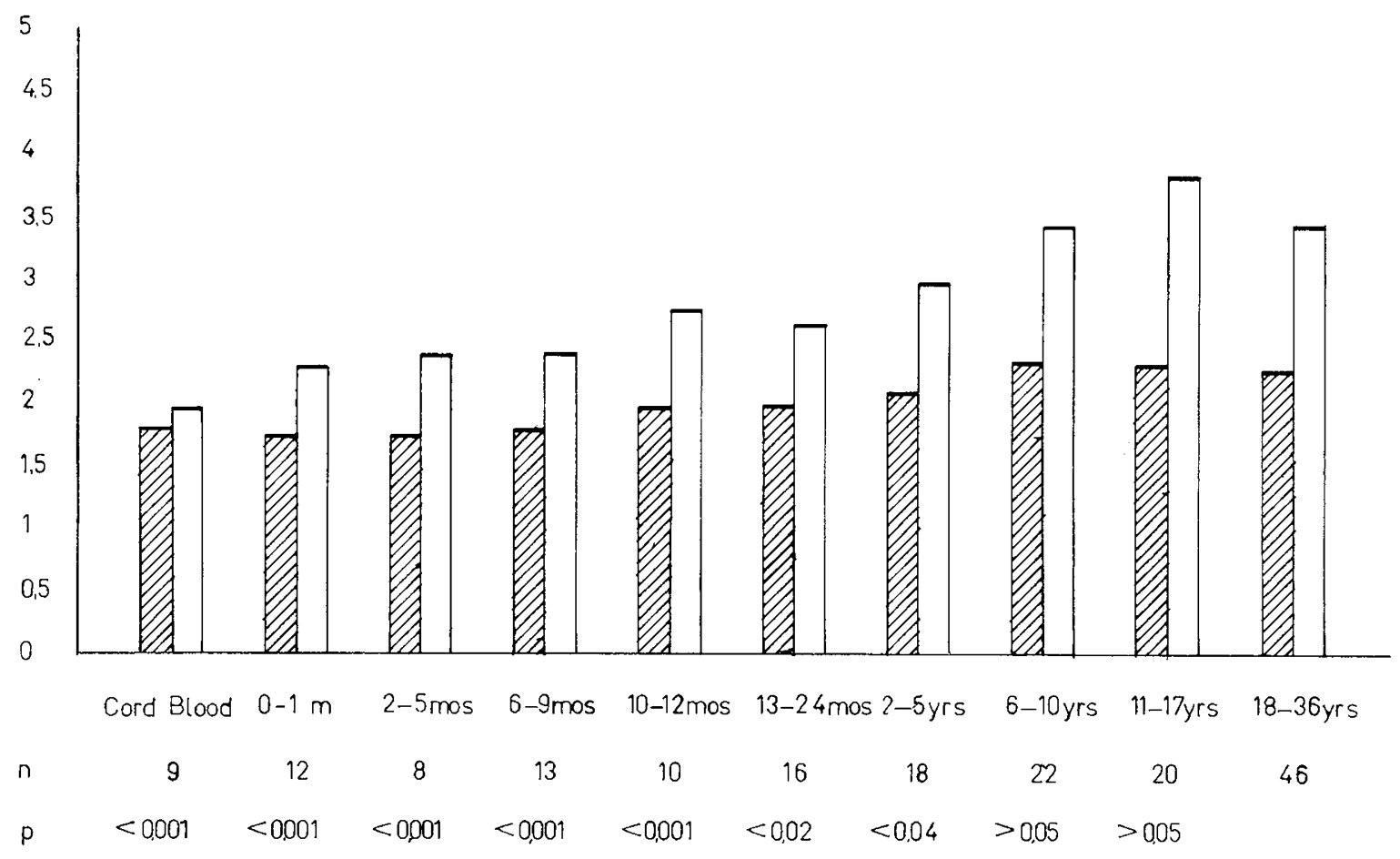

2 Chemotactic index for distance measurements

Chemotactic index for cell counts.

Fig. 3. Development of neutrophil chemotactic index (chemotaxis/random migration) in childhood.

correlation in this study. In addition, cell count and distance measurements correlated well in the agarose method; however, the agarose method and cell count determination seemed to be the most sensitive. Although neither the agarose nor the filter method can provide direct data for cell/cell interactions and kinetics of individual cell movement, they are easy, rapid, and reproducible methods suitable for clinical studies. Both the speed and number of phagocytes migrating to the invasion sites is important in prevention or control of infection, therefore determining both distances and cell numbers whereas evaluating chemotaxis seems to be more appropriate.

In the agarose method differences between adults and newborns were more marked in reference to cell counts than to distance measurements (Fig. 2). In addition, the observation of significantly high distance/cell count ratio in newborns when compared with adults in the agarose method suggested that the proportion of actively moving cells rather than speed is depressed during the neonatal period.

Al-Nakeeb et al. (1) reported a significant difference between $0-6-$ and 6-15-year-old groups in neutrophil random migration. In our study no difference was found between adults and newborns in the Boyden chamber and distance measurements by the agarose method as reported by others $(15,19)$, but cell counts were significantly lower in newborns and before 6 months of age. This finding stresses the necessity of a combined application of different methods and evaluation types in determining the locomotor capacity of neutrophils.

The mechanism of diminished locomotor capacity of neutrophils and monocytes in the early childhood period is unclear. Decreased membrane deformability of neonatal PMNs may explain the decreased chemotactic activity but the precise mechanism of this is also unexplained (16). Das et al. (6) noted energy dependent enzymatic defects in mononuclear leukocytes during the neonatal period. A maturational defect in energy production may interfere with energy dependent functions such as chemotaxis. Microtubule system dysfunction, which has been shown recently with concanavalin-A capping studies, in newborn neutrophils may be an explanation $(10,20,23)$, but further studies are needed for determining whether this represents a primary membrane abnormality or reflects a defect of cytoskeletal or other submembranous components.

Bellanti et al. $(2,3)$ demonstrated that there is a morphologic, biochemic, and functional maturational period both in PMNs and monocyte macrophage line. Decreased surface receptors, immature actin-myosin or cyclic nucleotide systems, which have not been investigated, may also be responsible.

Decreased PMN and monocyte chemotactic activity observed in the early childhood period may play an important role in contributing to the susceptibility to infection by diminishing the rapidity and quality of nonspecific inflammatory reactions or by failing to participate in the specific immune response.

\section{REFERENCES AND NOTES}

1. Al-Nakeeb, S. and Thompson, E. N.: Assessment of neutrophil chemotaxis and random migration in childhood. Arch. Dis. Child., 55: 296 (1980).

2. Bellanti, J. A., Cantz, B. E., Yang, M. C.. Thadden, H., Schlegel, R. J.: Biochemical changes in human polymorphonuclear leukocytes during maturation. In Bellanti, J. A., Dayton, D. H. (eds): The Phagocytic Cell in Host Resistance p. 321 (Raven Press, New York 1975).

3. Bellanti, J. A., Nerurkar, L.SS., Zeligs, B. J.: Host defences in the fetus and neonate: Studies of the alveolar macrophage during maturation. Pediatrics, 64 : 726 (1979).

4. Boyden, S. V.: The chemotactic effect of mixtures of antibody and antigen on polymorphonuclear leucocytes. J. Exp. Med., 115: 453 (1962).

5. Boyum, A.: Isolation of mononuclear cells and granulocytes from human blood. Scand. J. Clin. Lab. Invest., 21 (suppl 97): 77 (1968).

6. Das, M., Klein, W., and Feig, S. A.: Glycolytic metabolism of neonatal mononuclear cells. Pediatr. Res., 11: 1026 (1977).

7. Gallin, J. I., Wright, D. G., Malech, H. L., Davis, J. M., Klempner, M. S., and Kirkpatrick, C. H.: Disorders of phagocyte chemotaxis. Ann. Intern. Med., 92: 520 (1980).

8. Hill, A. and Bardford,: A short textbook of medical statistics 2. ed. (Hodder and Stoughton London 1978).

9. Kaplow, I. S.: Simplified myeloperoxidase stain using benzidine dihydrochloride. Blood, 26: 215 (1965).

10. Kimura, G. M., Miller, M. E., Leake, R. D., Raghunathan, R., Cheung, A. T. W.: Reduced concanavalin A capping of neonatal polymorphonuclear leukocytes (PMNS). Pediatr. Res., 15: 1271 (1981)

11. Klein, R. B., Fischer, T. J., Gard, S. E., Biberstein, M., Rich, K. C., and Stiehm, 
E. R.: Decreased mononuclear and polymorphonuclear chemotaxis in human newborns, infants and young children. Pediatrics, 60: 467 (1977).

12. Kretschmer, R. R., Stewardson, B. B., Papiernialo, C. K., and Gotoff, S. D.: Chemotactic and bactericidal capacities of human newborn monocytes. J. Immunol., 117: 1303 (1976)

13. Leddy, J. P., Baum, J., and Rosenfeld, S. I.: Genetic deficiencies of complemen derived chemotactic factors. In: "Leukocyte Chemotaxis" Gallin, J. I., Quie, P. G. (eds): pp 389 (Raven Press New York 1978).

14. Marodi, Z., Csorba, S., and Nagy, B.: Chemotactic and random movement of human newborn monocytes. Eur. J. Pediatr., I35: 73 (1980)

15. Miller, M. E.: Chemotactic function in the human neonate: Humoral and Cellular aspects. Pediatr. Res., 5: 487 (1971).

16. Miller, M. E.: Developmental maturation of human neutrophil motility and its relationship to membrane deformability. In: Bellanti, J. A., Dayton, D. H (eds) The Phagocytic Cell in Host Resistance: pp. 295 (Raven Press New York 1975).

17. Miller, M. E. and Cheung, A. T. W.: Characterization of the movement defect of human neonatal PMN's. Pediatr. Res. (Abstract), 14: 549 (1980)

18. Nelson, R. D., Quie, P. G., and Simmons, R. L.: Chemotaxis under agarose: a new and simple method for measuring chemotaxis and spontaneous migration of human polymorphonuclear leukocytes and monocytes. J. Immunol., 115 1650 (1975).

19. Pahwa, S. G., Pahwa, R., Grimes, E., and Smithwick, E.: Cellular and humoral components of monocyte and neutrophil chemotaxis in cord blood. Pediatr. Res., 11: 677 (1977).

20. Rister, M., Brucke, G., Horatz, M., and Feyerabend, M.: Maturation of neonatal neutrophils. Pediatr. Res. (Abstract), 15: 199 (1981).

21. Rosenfeld, S. I., Baum, J., Steigbigel, R. T., and Leddy, J. P.: Hereditary deficiency of the fifth component of complement in man: II. Biological properties of C5-deficient human serum. J. Clin. Invest., 57: 1635 (1976).

22. Snyderman, R. and Pike, M. C.: Disorders of leukocyte chemotaxis. Ped. Clin North. Am., 24: 377 (1977)

23. Strauss, R. G. and Hart, M. J.: Spontaneous and drug induced concanavalin A capping of neutrophils from human infants and their mothers. Pediatr. Res., 15: $1314(1981)$

24. Tono-Oka, T., Nakayama, M., Uehara, H., and Matsumoto, S.: Characteristics of impaired chemotactic function in cord blood leukocytes. Pediatr. Res., 13: 148 (1979).

25. Ward, P. A., Johnson, K. J., and Kreutzer, D. L.: Regulatory dysfunction in leukotaxis. Am. J. Pathol., 88: 701 (1977).

26. Weston, W. L., Carson, B. S., Barkin, R. M. Slater, G. E., Dustin, R. D., and Hecht, S. K.: Monocyte-macrophage function in the newborn. Am. J. Dis. Child., 13I: 1241 (1977).

27. Zigmond, S. H. and Hirsch, J. G.: Leukocyte locomotion and chemotaxis. New Methods for evaluation and demonstration of a cell derived chemotactic factor. J. Exp. Med., 137: 387 (1973).

28. Wellcome, Beckenham, U.K.

29. Sigma Chem. Corp. St. Louis Mous, U.S.A.

30. Bellco Glass Co. Vineland N.J. U.S.A

31. Millipore Corp. Bedford Mass. U.S.A.

32. Indibiose $A_{37} \mathrm{IBF}$, France.

33. Sterilin, Teddington Middlesex U.K

34. This study was supported by the Hacettepe Child Health Foundation.

35. Requests for reprints should be addressed to: Dr. Olcay Yeğin, Immunology Laboratory, Hacettepe Children's Hospital, Institute of Child Health, Hacettepe University Ankara, Turkey.

36. Received for publication January 20,1982

37. Accepted for publication June 11, 1982. 